\title{
Total Body Clearance by Fraction of Dose for Dose Interval
}

National Cancer Institute

\section{Source}

National Cancer Institute. Total Body Clearance by Fraction of Dose for Dose Interval. NCI Thesaurus. Code C114121.

The total body clearance for extravascular administration for dose interval, where $\mathrm{F}$ is the fraction of dose absorbed. 